\title{
Machine Learning Based DWDM Design Using Regression Modelling
}

Venkatesan K ( $\square$ venkatsri21@gmail.com )

St.Joseph's College of Engineering

\section{Chandrasekar A}

St.Joseph's College of Engineering

Ramesh P.G.V

St.Joseph's Institute of Technology

\section{Research}

Keywords: Optical parameters, FWM, DWDM, Regression modeling, Correlation

Posted Date: September 9th, 2020

DOI: https://doi.org/10.21203/rs.3.rs-44204/v2

License: (1) This work is licensed under a Creative Commons Attribution 4.0 International License. Read Full License 
The authors have withdrawn this preprint from Research Square 